\title{
The Master's Thesis: an Opportunity for Fostering Presentation Skills.
}

Manuel Arias, Member, IEEE, Pablo Pando, Alberto Rodriguez, Student Member, IEEE, Pablo F. Miaja, Member, IEEE, Aitor Vázquez, Student Member, IEEE, Marcos Fernández, Student Member, IEEE, and Diego G. Lamar, Member, IEEE

Abstract-Presentation skills, such as oral expression and public speaking, have normally been relegated to the background in engineering degree programs. In recent years, however, the labor market has specifically demanded these kinds of skills in engineers. Accordingly, new engineering degrees, adapted to the goals of the Bologna Declaration or ABET criteria, consider presentation skills as being fundamental transferable skills. In practice, however, many engineering degree programs do not specifically foster these skills even though they are included in the syllabus. This paper proposes a presentation-skills training that uses the Master's thesis as an opportunity for fostering presentation-related skills. This activity has students deliver a scheduled series of rehearsals, in front of their classmates and tutors, for their officially assessed presentation of their Master's thesis work. The paper also presents a Web tool specifically designed for uploading recordings of the rehearsal presentations for feedback online as a complementary method for fostering presentation-related skills. Finally, the results of carrying out the proposed resource over a four year period from 2009-13 are discussed; they show that students following the proposed methodology had higher than average marks, all receiving an $\mathrm{A}+$, and $82 \%$ of them receiving an $\mathrm{A}+$ with distinction.

Index Terms-Master's thesis, oral expression, presentation skills, transferable skills, Web tool 


\section{INTRODUCTION AND BACKGROUND}

Engineers are commonly expected to have the necessary technical and scientific knowledge to be able to solve problems or optimize systems in many fields [1], [2]. Bearing this in mind, in many countries engineering degrees are planned so that the first years of the programs impart basic knowledge that is mainly focused on mathematics and physics [3], and the later years focus on topics specific to the engineering field the student will specialize in. In the case of electronic engineering, courses are organized, generally, in a highly sequential way. From mathematics and physics, students move on to electronic devices and then to systems. Courses such as Power, Digital, and Telecommunication Electronics teach that systems are composed of several devices, each with different purposes and characteristics [3]; in these courses, lecturers help students integrate new knowledge and skills with those acquired in previous courses. This is general description is applicable to many, but not to all, curricula, which generally embody the concept of beginning with basic knowledge and progressing to more complex and specific knowledge.

It should be noted that engineering degrees ought not to focus solely on technical skills. Companies [4] demand a wide range of non-technical skills and techniques in novice engineers, such as oral and written expression [5]-[7], public speaking, critical thinking and teamwork [8]. In the past, all these skills were assumed to have been acquired by engineers during their degree, although no special effort was made to foster them during their courses. It has been shown, however, that this model is not longer adequate, and that these skills have to be specifically fostered during engineering degrees if industry demands are to be satisfied [9]-[11]. Accordingly,

the Bologna Declaration [12], [13] introduced the concept of transferable skills, proposing a change in methodology and making lecturers responsible for promoting these skills during degree 
courses. The nonprofit organization ABET, which accredits programs in the disciplines of applied science, also takes transferable skills into consideration; its criterion 3 includes the ability to communicate effectively as a mandatory student outcome [14]. The National Academy of Engineering (NAE) guidelines also points in the same direction [15]-[18].

Subsequent to the Bologna Declaration [19], many European universities therefore included a wide variety of transferable skills as targets in their engineering degrees [20], [21]. In fact, many curricula (of European and non-European Universities) include some of these skills as milestones, implying that courses should foster them [22]-[25]. In the case of oral expression and other presentation skills, many courses approach this goal by having students present a topic to the rest of the class. While this can help students overcome their fear of speaking in public, it will not help them make high-quality presentations unless specific training in these skills is built into the course. In the case of the Master's thesis (MT), fostering the skills needed for high-quality presentations is fundamental, given that part of the final assessment consists of students giving a presentation on their MTs before an examining board [7]. However, since presentation skills are often assumed to have been acquired during previous courses, no special effort is made in this area when working on the MT, and students focus only on the technical aspects of their MTs. Once the work is completed and thesis itself written, they prepare the slides for the official assessment presentation and show these to their tutor. In the days before the official assessment the student will have one or two rehearsals, during which the tutor points out some modifications. This may improve that particular presentation, but does not inculcate the skills necessary for giving high-quality presentations.

This paper presents a presentation-skills training implemented at the University of Oviedo, Gijon, Spain, which focused on the MT as a means to improve student presentation 
skills. First, all the necessary skills have to be explained, and students made aware of their importance. These skills include having confidence, clear diction and voice projection, and being able to prepare high-quality slides and engage the audience. Second, during their MT project students carry out a series of specially-designed exercises that help them gradually acquire and enhance all the skills necessary to make a high-quality presentation - the main goal of the proposed activity. The secondary goal is that of making students aware of the importance of presentation skills, both because their work will be assessed by means of their presentation and because these are skills required of engineers by the labor market [20], [26]. Even in universities that actively foster transferable skills during degree courses, the proposed methodology can be of great help in polishing these skills. The methodology has two key features: the advanced students are responsible for the beginners' learning process, and the proposed web tool enhances the learning opportunities for all the students.

The paper is organized as follows. Section II describes the content and organization of the introductory seminar in which students identify the basic presentation skills and techniques. The schedule and the training activities during the MT are presented in Sections III (regular supervised rehearsals) and IV (Web tool). Finally, conclusions are summarized in Section V.

\section{INTRODUCTORY SEMINAR}

The first stage for the students involved in the presentation-skills training is to attend a seminar, given by one of the MT tutors, which teaches the basic principles of a high-quality presentation, and conveys the need to practice every presentation as much as possible to polish it up. 


\section{A. Seminar Contents}

Before defining and planning the exercises of the presentation-skills training, it is essential to identify which techniques, concepts and skills need to be fostered to achieve a highquality presentation. The main aspects of a high-quality technical presentation (such as duration, audience or presentation room) in the academic field are explained in [27] and [28]. Some recommendations and an interesting comparison of the differences between experts' and students' techniques for designing slides are explained in [29]. Useful examples of typical errors and recommendations for avoiding them are presented in [30], focused not only on the slides, but also on the speech, the audience, the speaker and the question time. In [31], a classification of presentations according to their purpose is explained, and an interesting analysis is given of public-speaking anxiety and techniques to build confidence. Useful recommendations can be also found in [32], especially with respect to written and oral expression. Reference [33] provides some useful general hints for the design of slides according to the type of audience. An interesting study about the influence of headlines in information recall is presented in [34] while [35] is focused on the analysis of the well-known assertion-evidence structure in comparison to the traditional bullet-based structure. Another interesting proposal for the structure of slides is presented in [36], which also provides useful information for presentation delivery (e.g., speech, catching the audience's attention). Reference [37] introduces useful concepts in design and exposition. This is treated more specifically in [38], which deals with the influence of the type of font used in slides (analyzing four variables in functional and semantic properties of ten different fonts). A similar analysis focused on charts (bar graphs) can be found in [39]. 
In this introductory seminar, students are taught the key points of a successful presentation. In other words, this seminar is a summary of all the techniques, recommendations and examples from the literature (above). Fig. 1 presents the scheme and contents of the seminar. Note that this scheme is divided in three sections (planning, designing, and giving the presentation) according to the three levels of the students involved in the periodic rehearsals (see

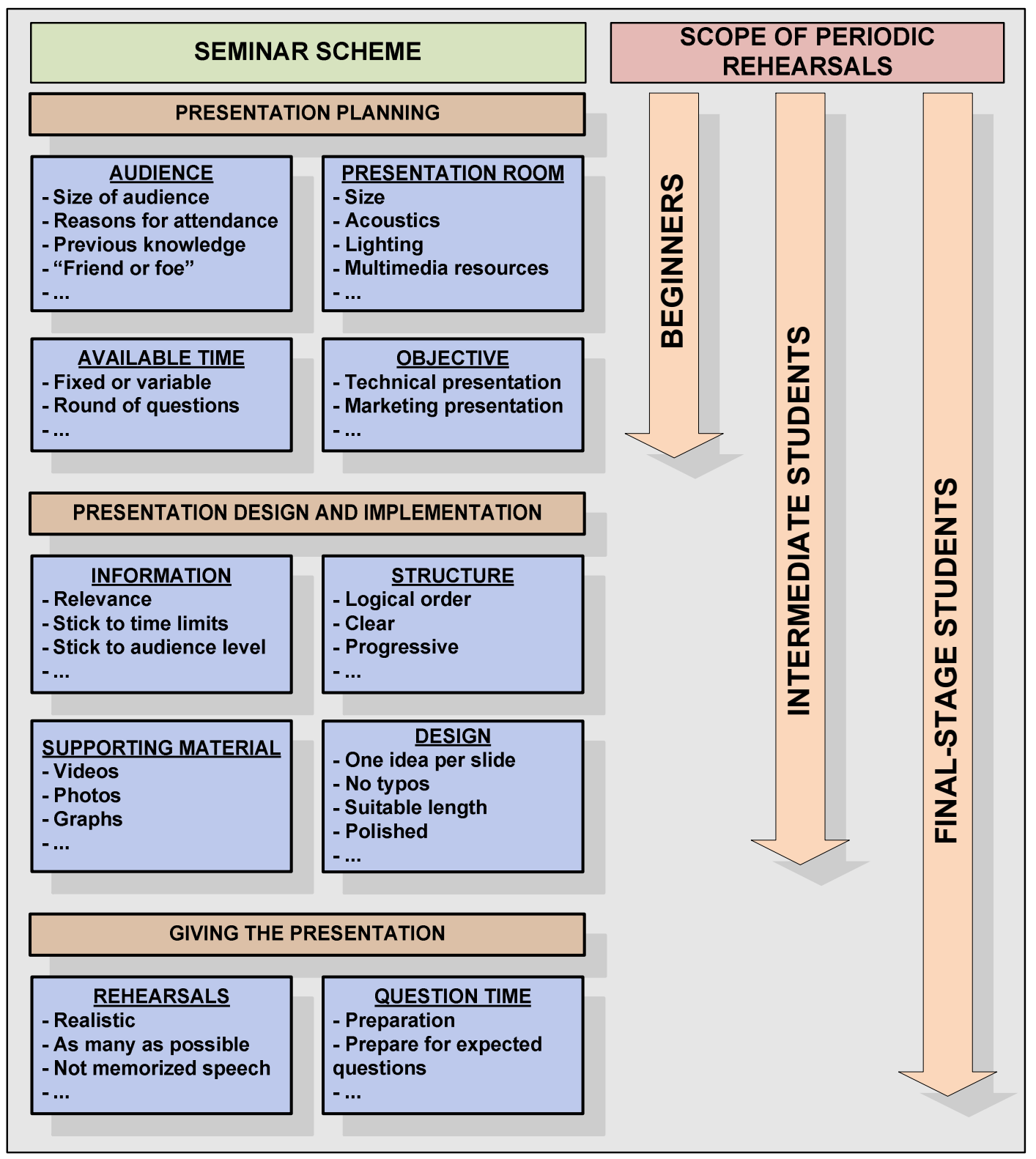

Fig. 1. Basic scheme of the seminar and scope of the periodic rehearsals for different types of students. 
Section III).

\section{B. Seminar Organization}

The seminar is structured as a model presentation that follows the generallyrecommended rules, to serve as an example for students. It is kept shorter than 30 minutes in length, the aim being to provide an overview of the key points to bear in mind when preparing a presentation, rather than to provide a full list of "dos and don'ts", which would lose students' attention by being too lengthy. The seminar also briefly explains the web tool and the process that will be followed during the activity.

The seminar instructors need not be familiar with the technical content of each MT, but they do need to be experts on technical communication and presentations. They have the experience and knowledge to convey the most important rules and recommendations, always taking into account that this seminar is just an introduction that will be built on with further material during the rehearsals.

\section{PRESENTATION REHEARSALS}

The main purpose of the rehearsals is for students to put into practice all the techniques and concepts introduced during the seminar. They take place in front of all the students and tutors, in the room in which the official MTs presentations are normally held. Each student presents the work they have done on their project. After each presentation, tutors correct and comment on the presentation, with variations according to student type.

Rubrics are used as a complement to these comments, Section V. These serve mainly to show students their progress as they work through the proposed activities, since students are more motivated by the tutors' comments and suggestions for improvement in specific areas than they are by assessment results. 
Other factors proved important in order for students to obtain satisfactory results. First is the frequency of the rehearsal meetings. After four years of running the rehearsals, it was concluded that each student should give three or four presentations during the seven- or eightmonth period in which they are working on their MTs.

During the rehearsal meetings, the projects presented are at different stages of completion. This is accommodated by adjusting the length of the presentations: new MTs (in their first two to three months) have five minutes, more advanced MTs (four to five months) have ten minutes, and MTs that are about to be presented for official assessment (seven to eight months) have 15-20 minutes. Not only does this avoid new students having excessive time in relation to the amount of work accomplished, but it also obliges students to plan their presentation according to the time available, since ignoring this is one of the most common mistakes made in giving presentations. Every MT student gives a presentation during each rehearsal meeting, whatever the stage of completion of their MTs, so the audience is composed of the three categories of beginner, intermediate and final-stage students. This allows the beginners to learn from the more experienced students, who are encouraged to help them. Being responsible for the beginners' learning process also improves the experienced students' results, a key feature of the proposed methodology.

The remaining factors will be explained below according to student type:

\section{A. Beginners}

Beginning students have been working on their project for two or three months and presumably have little experience in presentation techniques. Two weeks before their first rehearsal meeting, during which they will have to give a five-minute presentation, they students attend the introductory seminar. Since this provides more information than needed for this first 
presentation, they are therefore encouraged to concentrate their efforts on planning the presentation (Fig. 1) and on two fundamental points:

- The purpose and objectives of their MTs.

- The work already completed.

After each presentation, tutors should try to correct, and comment on, the planning of the presentation. In addition, some brief feedback on the graphic design of the slides and selection of the material may be given, without going into too much detail, as this will be addressed in the student's next presentation. The beginning students also learn about these aspects by listening to the comments and corrections made by tutors after the presentations of the intermediate and finalstage students - an advantage of mixing the different levels of student. Students thus have the opportunity to learn not just from their own presentation, but also from all the presentations given during the rehearsal meeting, particularly since the intermediate and final-stage students give feedback to beginning students. This increases their involvement by making them responsible for improving the quality of their classmates' presentations.

\section{B. Intermediate Students}

At this stage, students have invested four or five months in their MTs, have attended at least one rehearsal meeting as beginning students, and can recall what they learnt during that experience.

These students are asked to focus on presentation design and material selection (Fig. 1), as well as applying all the skills and techniques that they learnt in the previous rehearsals. Tutors should use intermediate student presentations not only to train these students, but also as a learning resource for beginners. Providing a full list of requirements for a high-quality 
presentation during the introductory seminar is difficult; it is far easier, and more useful, to illustrate these using real presentations.

As already mentioned, intermediate students also help tutors correct beginner students. Tutors have to pay careful attention to their comments and suggestions, however, to keep the process under strict control and to avoid unhelpful suggestions which could demotivate the beginning students.

A question period is introduced in this intermediate stage, with the other students and the tutors posing questions at the end of each intermediate presentation. This gives the students practice in answering questions, and gradually reduces their anxiety. This being the first time that the student has had to deal with a round of questions, it is strongly recommended that it should last no longer than five minutes (three or four questions). Tutors should behave as a moderator, being alert for questions that are too difficult for the student at this stage of his/her MT.

\section{Final-Stage Students}

This group consists of students who have completed at least $90 \%$ of their MTs, and students who have completed but not yet defended their MTs. These latter students may need a specially-scheduled rehearsal meeting if the regular meeting date does not coincide with the completion of their MT. In such a case, only the student about to defend his/her MT will give the rehearsal presentation, with the audience still being made up of the remaining students and tutors.

In these rehearsals (see Fig. 1), corrections and comments are focused on the presentation itself. Even the tiniest detail should be corrected, seeing the presentation as a "simulation" of the final defense of the MT. The purpose here is twofold: to obtain a high-quality presentation to improve the official assessment result, and to teach students (both the presenter and the audience) 
presentation techniques in areas such as catching the audience's attention, voice projection, or staying focused.

The question round should be as similar as possible to that of the official defense presentation. Tutors should therefore formulate technically complex questions, query some technical decisions to force their justification, and, in general, behave as the official examining board in order to prepare the student. Some of these questions will probably come up in the official MT defense presentation. The tutor and the student should get together at the end of the meeting and make sure that the answers to these questions are both understood and well prepared by the student.

\section{WEB TOOL FOR REMOTE SUPERVISED REHEARSALS}

During the first years of the rehearsal activity, a problem was encountered. Sometimes a student could not attend the meeting because of conflicting classes or for personal reasons (roughly $10 \%$ of the students miss one of the rehearsals). Consequently, this student misses the opportunity of receiving feedback about his/her presentation, and of learning from his/her other classmates' presentations. Since a student will only attend three or four meetings, missing even one implies a $25 \%$ reduction in the efficacy of the methodology.

A web application ${ }^{1}$ was developed by the tutors involved to solve this problem. Using this web application, students can upload videos of their presentations so that they can be assessed by the other students and tutors at any time. This application also has the important advantage that it

${ }^{1} \mathrm{~A}$ web account has been created to test the proposed web tool (seehttp://pels.edv.uniovi.es/WebPres/index.php). This web account can be used by anyone and provides access to one of the groups recently created. The user name is guest and the password is guest. 
allows an unlimited number of rehearsals; student can upload as many practice presentations as they wish. In this way, students who are very interested in improving their presentation skills may record more presentations (carried out at home or elsewhere) and upload them for assessment.

Broadly speaking, once a student uploads a recorded presentation, the other students and tutors can watch it and add comments. These comments include a time reference so that they can refer to a certain moment or period of the presentation. When someone has finished reviewing a presentation, the author receives an email, copied to the tutors, informing him/her of the new set of comments.

This is only a brief description of the web tool from an educational point of view, and does not cover advantages such as its encouragement of student participation, or its tools that allow tutors moderate the comments.

\section{ASSESSMENT}

An evaluation of the activities was made from the students' results in their MTs assessments, and by interviewing students as to their opinion of the effectiveness of the activities.

A brief description of the University of Oviedo's regulations for MTs will clarify the results of the assessment and related concerns presented in this section. Each academic year, some thirty tutors (of whom six use the rehearsal methodology) propose a number of MT topics to the Master's Committee. The Committee presents these to the students, each of whom then submits a list of their preferences. The Committee then assigns the MT topics taking these preferences into account as far as possible. Therefore tutors cannot choose the students that are enrolled in their MTs and the students are not normally aware of the methodology that each tutor follows. Their preferences are based on the topic and on the tutor rather than according to the methodology that is going to be followed. Once the MTs have been assigned, the ratio of students 
enrolled in the rehearsal methodology to the total number of Master's students mirrors that of the tutors (six to thirty). The tutors using the rehearsal methodology inform the students about the methodology as part of their orientation. With certain limits, each tutor is free to set certain rules for the realization of the MTs he/she is supervising - including making the rehearsal methodology mandatory for all his or her students, should the tutor be using it. The methodology also helps fulfill the requirement that $10 \%$ of the students' MT credit has to be based on on-line classes or tutorials. The MTs are assessed by an examining board of three lecturers, none of whom can be the tutor of the MT under evaluation, so as to preserve objectivity. The examining board does receive a confidential report from the MT tutor in the evolution and quality of the student's work.

The first concern is that the student presentations should be up to the standard of their rehearsals. The authors' previous experience with other activity-based methodologies in other courses showed that the final results were of lower quality than those obtained during the activities themselves, due to anxiety, different examining boards, or other issues. Therefore, it was expected that the quality of the rehearsal presentations would be higher than that of the MT defense presentation itself.

Rubrics [40]-[44] are used during the rehearsal meetings; the introductory seminar does not include any kind of assessment. The purpose of these rubrics is to show students the evolution and improvement in their presentation skills, rather than the tutors assessing them. Initially, the University's rubrics for the official assessment of the MT were used. However, these do not have the detail necessary for the rehearsal activity and are not a good complement to the comments and suggestions made by tutors and other students. Furthermore, the official rubrics focus the student too much on the results of the rubrics rather than on the comments and suggestions. For 
example, beginning students worry because their results in the first rehearsal are not as high as they would like. Therefore, specially-designed rubrics were used for the rehearsals (Table 1). These rubrics have been under a continuous process of change and optimization since the second year of this presentation-skills training. Apart from being more detailed, the scale of the rubrics used during the rehearsals has a range from 1 to 4, while that of the University rubrics ranges from 0 to 5; this change helps to focus students on improving their presentation skills rather than on just increasing their mark). The fields covered by the rubrics have also evolved, and have been improved by paying attention to the most common student mistakes during rehearsals. Therefore, nearly any comment or suggestion can be related to one of the topics of the rubrics and, also, to one of the three main issues described in the introductory seminar (see Section II). This makes it easy for students to see the relationship between a suggestion (or comment) and its impact on the presentation quality.

Table 1. Rubrics used to assess presentations during rehearsals.

\begin{tabular}{|c|c|c|c|c|}
\hline & 4 & $\mathbf{3}$ & 2 & 1 \\
\hline Body position and eye contact & $\begin{array}{l}\text { Seems self-confident. } \\
\text { Eye contact during the } \\
\text { presentation. }\end{array}$ & $\begin{array}{c}\text { Good body position } \\
\text { and eye contact } \\
\text { nearly all the time. }\end{array}$ & $\begin{array}{c}\text { Average body } \\
\text { position and eye } \\
\text { contact sometimes. }\end{array}$ & $\begin{array}{l}\text { Bad body position } \\
\text { and no eye contact. }\end{array}$ \\
\hline Voice level & $\begin{array}{l}\text { All the audience can } \\
\text { hear what is said. }\end{array}$ & $\begin{array}{l}90 \% \text { of the } \\
\text { audience can hear } \\
\text { what is said. }\end{array}$ & $\begin{array}{c}60 \% \text { of the } \\
\text { audience can hear } \\
\text { what is said. }\end{array}$ & $\begin{array}{l}\text { The audience } \\
\text { complains about not } \\
\text { being able to hear } \\
\text { the speaker well. }\end{array}$ \\
\hline Diction & $\begin{array}{c}\text { Words can be clearly } \\
\text { understood. }\end{array}$ & $\begin{array}{l}\text { Words can be } \\
\text { understood nearly } \\
\text { all the time }(90 \%) \text {. }\end{array}$ & $\begin{array}{c}\text { Words can be } \\
\text { understood many } \\
\text { times }(70 \%-80 \%) \text {. }\end{array}$ & Poor diction. \\
\hline Know-how & Higher than required. & Required. & $\begin{array}{l}\text { Lacking in certain } \\
\text { fields. }\end{array}$ & $\begin{array}{l}\text { Important overall } \\
\text { lack of knowledge. }\end{array}$ \\
\hline Answering questions & $\begin{array}{l}\text { Adequate answers to } \\
\text { nearly all questions. }\end{array}$ & $\begin{array}{l}\text { Adequate answers } \\
\text { to many questions. }\end{array}$ & $\begin{array}{l}\text { Adequate answers } \\
\text { to some questions. }\end{array}$ & $\begin{array}{c}\text { Unsatisfactory } \\
\text { answers. }\end{array}$ \\
\hline Time & $\begin{array}{l}\text { All topics explained in } \\
\text { the time available. }\end{array}$ & $\begin{array}{l}\text { A certain rush at } \\
\text { the end to keep to } \\
\text { the allotted time or } \\
\text { runs slightly over } \\
\text { time. }\end{array}$ & $\begin{array}{c}\text { Runs moderately } \\
\text { over time. }\end{array}$ & Poor time planning. \\
\hline Catching the audience's attention & $\begin{array}{l}\text { Audience's attention } \\
\text { held at all times. }\end{array}$ & $\begin{array}{c}\text { Audience's } \\
\text { attention is } \\
\text { virtually not lost. }\end{array}$ & $\begin{array}{c}\text { Audience's } \\
\text { attention is lost } \\
20 \% \text { of the time. }\end{array}$ & Audience is bored. \\
\hline Organization & $\begin{array}{c}\text { Well organized and } \\
\text { planned. }\end{array}$ & $\begin{array}{l}\text { Some sections are } \\
\text { confusing. }\end{array}$ & $\begin{array}{l}\text { Many sections are } \\
\text { confusing. }\end{array}$ & Badly organized. \\
\hline Graphs, tables and photos & $\begin{array}{c}\text { All are interesting and } \\
\text { useful. }\end{array}$ & $\begin{array}{l}\text { Many are relevant } \\
\text { and interesting. }\end{array}$ & $\begin{array}{c}\text { Some are not } \\
\text { important and may } \\
\text { be removed. }\end{array}$ & Most are not useful. \\
\hline Typos & None. & One or two. & Three or four. & More than four. \\
\hline
\end{tabular}


As has been said, the rubrics used in the rehearsals have evolved over the years. This, added to their non-assessment purpose, implies that the official results obtained by students in the official assessment are a better indicator of the effectiveness of the proposed methodology. It should be also pointed out that the tutor of the MT never sits on the official MT examining board. Hence, analyzing the results obtained by the methodology's students in their actual MT defense is the most objective way of showing the positive results of the activity. Fig. 2 shows the results (rubrics) obtained during the official assessment (MT defense) over the academic years 20082011, which, as can be seen, are quite promising. The number of assessed students involved in the methodology is highlighted (5, 6 and 11) in the lower part of each group of the histogram. For

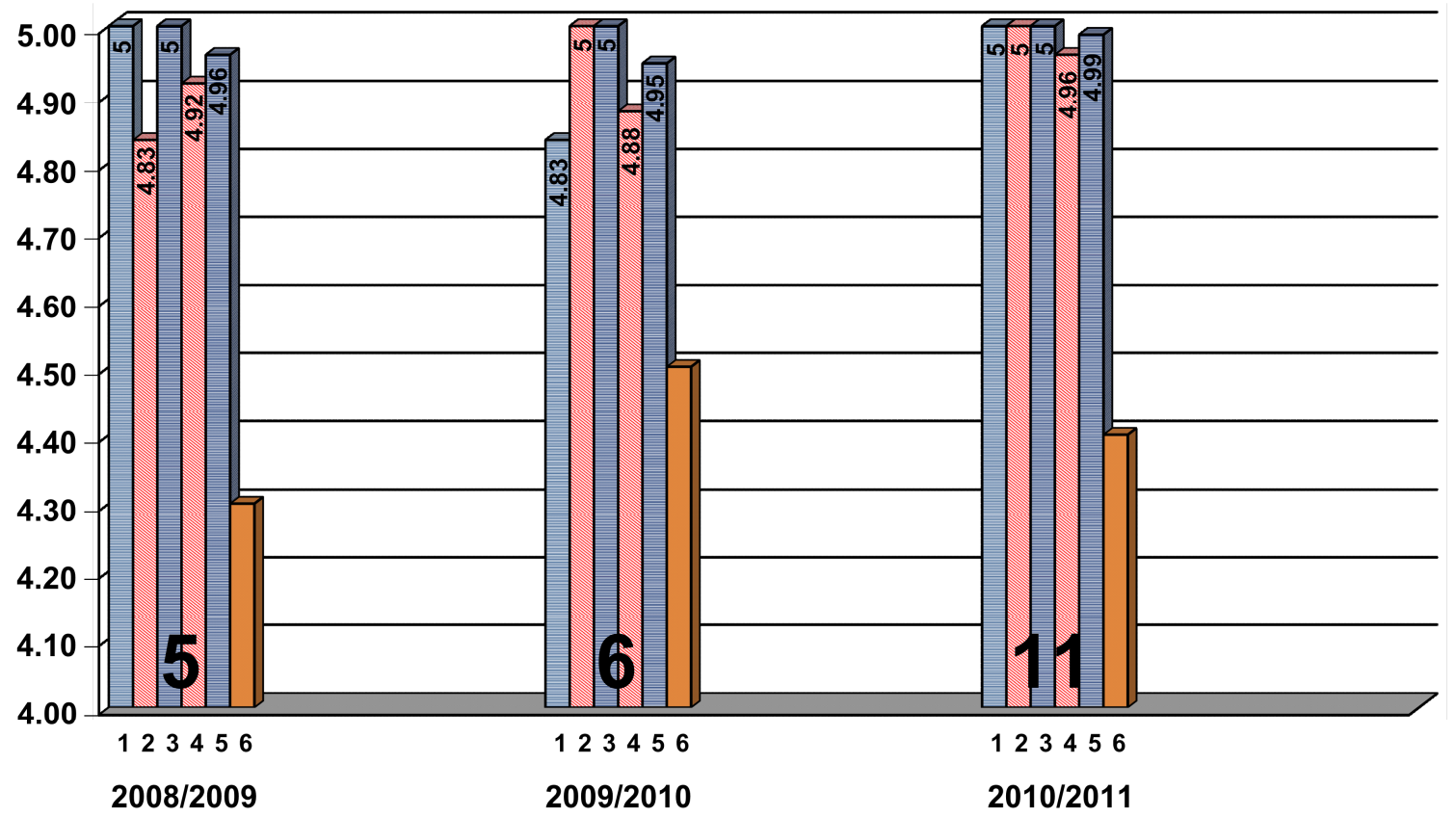

1- Quality of the presentation: oral expression, organization, etc.

2- Gaining the audience's attention

3- Answers to the examining board's question

4- Quality of the MT report

5- Overall mark

6- Average mark of all the MTs of the degree

Fig. 2. Assessment results during the years 2008-2011 
each group, the first, second and third bars respectively indicate the average mark obtained by students in different rubrics for the presentation (quality, answers to questions, gaining the audience's attention). The fourth bar represents the assessment of the MT documentation and the fifth, the results in the overall assessment. For all these results, the maximum mark is 5 . As can be seen, the official results are excellent, not only in terms of student presentations, but also in terms of the quality of the MT and the documentation provided (both of which fall outside the scope of this paper). Consequently, all the students received an $\mathrm{A}+$ and, eighteen of them, an $\mathrm{A}+$ with distinction.

Fig. 2 also shows the average mark that all the students of the degree (not only of those enrolled in the proposed activity) obtained in the years analyzed. As can be seen, the results of the students involved in the activity are higher than the average. Again, these students are not selected according to their results in the degree courses; any MT student under the supervision of a tutor using the rehearsal activity is enrolled in it. So the results are not a consequence of selecting only brilliant students for the seminars and rehearsals; students from across the spectrum have taken part in the activity and all of them improved the quality of their presentations and obtained a higher-than-average mark in the official assessment.

\section{CONCLUSIONS}

The first concern, as stated above, was that the student presentations should be up to the standard of their rehearsals, and it was expected that the quality of the rehearsal presentations would be higher than that of the MT defense presentation itself. But can be concluded that the quality of the presentations given by the students during their MT defense was not lower than the quality during rehearsals. Hence, the proposed activities prepare students well for any actual presentation, not only for the official MT defense. 
The second concern about this methodology was that it demands tutors to invest more time. However, the main time and motivation issue arises for students, not tutors. Using resources of this kind (web applications, interaction during supervised meetings) normally means that students tend to invest more time than recommended in preparing their presentations or recording videos. Therefore, tutors should ensure that students do not invest an excessive amount of time in presentation issues.

Also, this methodology presents the dangers as well as the advantages of working in a group. During supervised rehearsals, when one of the students has finished his/her presentation, all the audience (tutors and students) makes recommendations and gives advice. The advantages of this include participation and critical analysis. But drawbacks that may arise include excessive criticism, loss of motivation due to slow progress, or lack of participation for a variety of reasons. To avoid these problems, tutors need to behave as moderators, which constitutes one of their key tasks during supervised rehearsals.

Finally, the application of a new learning tool requires investment. If a new methodology is applied, instead of traditional ones, then the facilities to develop this new methodology also have to change. In the University of Oviedo, each MT represents 0.4 credits per year for the tutor (and up to 30 credits for the student); this valuation is not increased for the tutors taking part in the methodology. This situation is not adequate if this kind of methodology is to be broadly implemented. The methodology as described is possible because the number of students involved is low and because the tutors involved invest spare time in correcting the presentations. In any university in which MTs are allocated a significant amount of working hours, or even in a university in which this kind of initiative is welcome and provided with resources, this methodology can be implemented without any problem. 
Classifying students according to their stage in their MT allowed those with more experience to help those with less experience. Acting as an "advisor" to other students involves them in the methodology and helps them in their own gradual learning process. It also makes the most efficient use of tutors' time.

The web tool not only ensures the continued learning of students who are obliged to miss the rehearsals through schedule conflicts or any other unexpected event, but also allows students unlimited practice with feedback from tutors and classmates. Furthermore, it permits students to see their own presentations, a valuable way to recognize what improvements need to be made.

The methodology has proven to be useful in terms of the results obtained by the students in MTs, which is partly based on the quality of their presentations. The results they obtained were higher than the average, with eighteen of them receiving a distinction.

\section{REFERENCES}

[1] M. Saleh, "Challenges in engineering education: A view towards the future," in Conf. Rec. 2009 IEEE Int. Conf. E-Learning in Ind. Electron., , pp. 141-144.

[2] J. Lei, C. Zixue, W. Junbo, and Z. Yinghui, "A Spiral Step-by-Step Educational Method for Cultivating Competent Embedded System Engineers to Meet Industry Demands," IEEE Trans. Edu., vol. 54, pp. 356-365, Aug. 2011.

[3] E. Montero and M. J. Gonzalez, "Student Engagement in a Structured Problem-Based Approach to Learning: A First-Year Electronic Engineering Study Module on Heat Transfer," IEEE Trans. Edu., vol. 52, pp. 214-221, May 2009.

[4] D. Broman, K. Sandahl, and M. Abu Baker, "The Company Approach to Software Engineering Project Courses," IEEE Trans. Edu., vol. 55, pp. 445-452, Nov. 2012.

[5] D. Winsor, Writing like an engineer: a rhetorical education, Ed. New Jersey: Lawrence Erlbaum associates, Inc., 1996.

[6] D. Winsor, "Owning corporate texts," Journal of Bus. and Tech. Commun., vol. 7, pp. 179-195, Apr. 1993.

[7] J. D. Ford, "Knowledge transfer across disciplines: tracking rhetorical strategies from a technical communication classroom to an engineering classroom," IEEE Trans. Commun., vol. 47, pp. 301315, Dec. 2004. 
[8] D. Lopez, F. Sanchez, J. L. Cruz, and A. Fernandez, "Developing non-technical skills in a technical course," in Conf. Proc. Frontiers In Educ. Conference - Global Engineering: Knowledge Without Borders, Opportunities Without Passports, , pp. F3B-5-F3B-10, Oct. 2007.

[9] J. Garcia and A. Hernandez, "Active Methodologies in a Queueing Systems Course for Telecommunication Engineering Studies," IEEE Trans. Edu., vol. 53, pp. 405-412, Aug. 2010.

[10] C. Savander-Ranne, O. P. Lunden, and S. Kolari, "An Alternative Teaching Method for Electrical Engineering Courses," IEEE Trans. Edu., vol. 51, pp. 423-431, Nov. 2008.

[11] L. Horvath and I. J. Rudas, "Joint Student Projects of Higher Education Institutes and Industrial Companies Using Virtual Engineering Portal," in Conf. Proc. Int. Conf. Inform. Technology Based Higher Educ. and Training, , pp. 394-400, July 2006.

[12] The European Higher Education Area-- The Bologna Declaration of 19 June, 1999, Ed. European Comission, Bologna, Italy, 1999.

[13] M. J. Martins, J. M. Thiriet, O. Bonnaud, M. Hoffmann, M. Robert, J. Benlloch, and G. Jervan, "A survey of the evolution of the Bologna Process in EIE in Europe," in Conf. Proc 19th EAEEIE Annual Conference, , pp. 100-103, June-July 2008.

[14] Criteria for accrediting engineering technology programs, 2013 [Online]. Available: http://www.abet.org/uploadedFiles/Accreditation/Accreditation_Process/Accreditation_Docu ments/Current/tac-criteria-2012-2013.pdf.

[15] L. Lattuca, P. Terenzini, J. Volkwein, and G. Peterson. The changing Face of Engineering education, 2013 [Online]. Available: http://www.nae.edu/File.aspx?id=7396

[16] J. D. Ford and T. Scott, "The Right Answer Is Communication When Capstone Engineering Courses Drive The Questions," Journal of STEM Educ.: Innovations \& Research, vol. 7, July 2006.

[17] J. D. Ford and L. A. Riley, "Integrating Communication and Engineering Education: A Look at Curricula, Courses, and Support Systems," Journal of Eng. Educ., vol. 92, pp. 325-328, Oct. 2003.

[18] NAE, The Engineer of 2020: Visions of Engineering in the New Century. Washington, DC: The National Academy Press, 2004

[19] R. Magdalena, A. J. Serrano, J. D. Martin-Guerrero, A. Rosado, and M. Martinez, "A Teaching Laboratory in Analog Electronics: Changes to Address the Bologna Requirements," IEEE Trans. Edu., vol. 51, pp. 456-460, Nov. 2008.

[20] Mohan, D. Merle, C. Jackson, J. Lannin, and S. S. Nair, "Professional Skills in the Engineering Curriculum," IEEE Trans. Edu., vol. PP, pp. 1-1, Nov. 2010.

[21] R. Feldt, M. Host, and F. Luders, "Generic Skills in Software Engineering Master Thesis Projects: Towards Rubric-Based Evaluation," in Conf. Proc. Conf. on Software Eng. Educ. and Training, , pp. 12-15, Feb. 2009.

[22] R. Garcia-Robles, F. Diaz-del-Rio, S. Vicente-Diaz, and A. Linares-Barranco, "An eLearning Standard Approach for Supporting PBL in Computer Engineering," IEEE Trans. Edu., vol. 52, pp. 328-339, Aug. 2009.

[23] J. Dyke Ford. 2012, Integrating Communication into Engineering Curricula: An Interdisciplinary Approach to Facilitating Transfer at New Mexico Institute of Mining and Technology, 2013 [Online]. Available: http://compositionforum.com/issue/26/new-mexico-tech.php

[24] J. D. Ford, "Student Perceptions Of Communication: Undergraduate Engineers' Views Of Writing And Speaking In The Classroom And Workplace.," Journal of STEM Educ.: Innovations \& Research, vol. 7, pp. 34-50, Jan-Jun 2006.

[25] F. Gider, B. Likar, T. Kern, and D. Miklavcic, "Implementation of a Multidisciplinary Professional Skills Course at an Electrical Engineering School," IEEE Trans. Edu., vol. 55, pp. 332340, Aug. 2012. 
[26] M. Host, R. Feldt, and F. Luders, "Support for Different Roles in Software Engineering Master's Thesis Projects," IEEE Trans. Edu., vol. 53, pp. 288-296, May 2010.

[27] H. E. Hand, "Technical Speech: A Need for Teaching and Research," IEEE Transactions on Engineering Writing and Speech, vol. 10, pp. 48-51, Dec. 1967.

[28] S. Roger and M. Cobos, "Developing your electrical engineering degree thesis [Personal and Professional Growth]," IEEE Potentials, vol. 28, pp. 12-16, July-Aug. 2009.

[29] J. Mackiewicz, "Comparing PowerPoint experts' and university students' opinions about PowerPoint presentations," Journal of Tech. writing and commun., vol. 38, no 2, pp. 149-165, 2008.

[30] M. Alley, The craft of scientific presentations: critical steps to succeed and critical errors to avoid, Ed. New York: Springer-Verlag, 2003.

[31] L. Gurak, Oral presentations for technical communication, Ed. Pearson Education, 2000.

[32] R. Irish and P. Weiss, Engineering communication: from principles to practice, Oxford University Press, 2009.

[33] V. O. K. Li, "Hints on writing technical papers and making presentations," IEEE Trans. Edu., vol. 42, pp. 134-137, May 1999.

[34] M. Alley, M. Schreiber, K. Ramsdell, and J. Muffo, "How the design of headlines in presentation slides affects audience retention," Technical communication, vol. 53, pp. 225-234, May 2006.

[35] J. Garner, M. Alley, A. Gaudelli, and S. Zappe, "Common use of PowerPoint versus assertionevidence structure," Technical communication, vol. 56, pp. 331-345, Nov. 2009.

[36] G. Reynolds, Presentation Zen: simple ideas on presentation design and delivery, Ed. Berkeley: Pearson Education, 2008.

[37] A. G. Gross and J. E. Harmon, "The Structure of PowerPoint Presentations: The Art of Grasping Things Whole," IEEE Trans. Commun., vol. 52, pp. 121-137, June 2009

[38] J. Mackiewicz, "Audience perceptions of fonts in projected powerpoint text slides," Technical communication, vol. 54, pp. 295-307, Aug. 2007.

[39] J. Mackiewicz, "Perceptions of clarity and attractiveness in Powerpoint graph slides," Technical communication, vol. 54, pp. 145-156, May 2007.

[40] F. Martinez, L. C. Herrero, and S. de Pablo, "Project-Based Learning and Rubrics in the Teaching of Power Supplies and Photovoltaic Electricity," IEEE Trans. Edu., vol. 54, pp. 87-96, Feb. 2011.

[41] R. K. Boettger, "Rubric Use in Technical Communication: Exploring the Process of Creating Valid and Reliable Assessment Tools," IEEE Trans. Commun., vol. 53, pp. 4-17, March 2010.

[42] S. Barney, M. Khurum, K. Petersen, M. Unterkalmsteiner, and R. Jabangwe, "Improving Students With Rubric-Based Self-Assessment and Oral Feedback," IEEE Trans. Edu., vol. 55, pp. 319-325, Aug. 2012.

[43] Create Rubrics for your Project-Based Learning Activities, 2013 [Online]. Available: http://rubistar.4teachers.org/index.php

[44] S. Thomas, "The engineering-technical writing connection: a rubric for effective communication," in Conf. Proc. Professional Communication International Conference, , pp. 517-523, July 2005.

\section{ACKNOWLEDGEMENTS}

This work has been supported by University of Oviedo under project PINN12-015. 
Manuel Arias (S'05-M'10) was born in Oviedo, Spain, in 1980. He received the M.Sc. and the Dr.Eng. degrees in electrical engineering from the University of Oviedo, Gijón, Spain, in 2005 and 2010, respectively.

Since 2005 he has been a researcher in the Power Supply System Group, Oviedo. His research interests include AC-DC and DC-DC power supplies and their application in several fields, such as LED lighting or UPSs.

Pablo Pando received the M.Sc. degree, and the Dr.Eng. degree in electronic engineering from the University of Oviedo, Spain in 2003 and 2006, respectively.

$\mathrm{He}$ is currently a professor of computer-assisted design-related courses with the Department of Construction and Manufacturing Engineering, University of Oviedo. His research interests include computational geometry, medical image analysis, and interactive multimedia systems, specifically innovative ways to teach engineering concepts with multimedia software and to improve spatial perception.

Alberto Rodríguez (S'07) was born in Oviedo, Spain, in 1981. He received the M.S. degree in telecommunication engineering in 2006 from the University of Oviedo, Gijón, Spain, where he is currently working towards the Dr.Eng. degree.

In 2006, he was a telecommunications engineer with the Government of the Principality of Asturias and an Assistant Professor with the Department of Electrical Engineering, University of Oviedo. Since 2007 he has been working in University of Oviedo at full time.

His research interests are focused on multiple port power supply systems, bidirectional DC-DC power converters and wide band gap semiconductors. 
Pablo F. Miaja (S'07 M'13) was born in Oviedo, Spain, in 1984. He received the M.S. degree in telecommunication engineering from the University of Oviedo in 2007 and in 2012 the $\mathrm{PhD}$. degree from the same university.

Since December 2007 he works as a researcher at the Electronic Power Supply Systems Group of the University of Oviedo. His research interests include DC-DC conversion, digital control of switched converters and power-supply systems for RF amplifiers.

Aitor Vázquez (S'10) was born in Oviedo, Spain, in 1984. He received the M.Sc. degree in telecommunication engineering from the University of Oviedo, Gijón, Spain, in 2009, and he is currently pursuing the Ph.D. degree in the same university.

He became a member of the Power Supply System Group, University of Oviedo, in 2010. His research interests include modularization techniques applied to bidirectional dc-dc converters for HEV, power-factor corrector AC-DC converters, and energy recovery systems.

Marcos Fernández (S'11) was born in Avilés, Spain, in 1986. He obtained the degree in telecomunications engineering in 2011 in the University of Oviedo, Gijón, Spain.

He has been working in the Department of Electrical and Electronical Engineering, Computers and Systems, University of Oviedo, for the Power Supply System Group since 2011. His research interests include power factor corrector AC-DC converters for LED lighting.

Diego G. Lamar (S'05-M'08) was born in Zaragoza, Spain, in 1974. He received the M.Sc. and the Dr.Eng. degrees in electrical engineering from the Universidad de Oviedo, Gijón, Spain, in 2003 and 2008, respectively.

In 2003 and 2005 he became a Research Engineer and an Assistant Professor respectively at the University of Oviedo. Since September 2011, he has been an Associate Professor. His 
research interests are focused in switching-mode power supplies, converter modeling, and powerfactor-correction converters. 